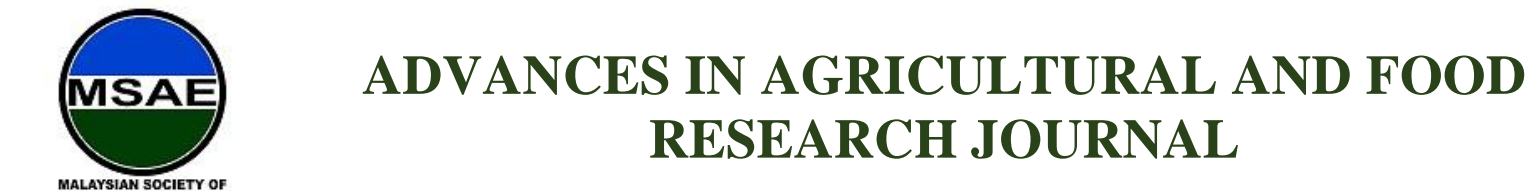

HH PUBLISHER

Original Research Article

\title{
Hydraulic Performance Analysis of Drip Irrigation System Using Pressure Compensated Dripper at Low Operating Pressure
}

Eddy Herman Sharu ${ }^{1 *}$

${ }^{1}$ Engineering Research centre, Malaysia Agriculture Research and Development Institute (MARDI), 43400

Serdang, Selangor, Malaysia; edherman@mardi.gov.my

*Corresponding author: Eddy Herman Bin Sharu, Address; Engineering Research centre, Malaysia Agriculture Research and Development Institute (MARDI), 43400 Serdang, Selangor, Malaysia; edherman@mardi.gov.my

\begin{abstract}
Irrigation is the most important component in ensuring that crops can produce optimal yields. The use of drip irrigation can help farmers provide water to crops in the amount required by the crop. Drip irrigation usually uses an uncompensated dripper and also a pressure compensated dripper. When using an uncompensated dripper, precise pressure is required to ensure a uniform flow for each dripper, while when using a pressure compensated dripper, operating pressure must be kept within the range defined by the dripper manufacturer. This research aims to compare the hydraulic performance of a low-pressure drip irrigation system to the minimum pressure recommended by dripper manufacturers. The pressure operation recommended by the manufacturer was 1.5-4 bars. This study uses pressures as low as 1 bar (low pressure), 2 bars, and 2.5 bars (recommended by manufacture) to operate this irrigation system. The volumetric approach was used to calculate each emitter's flow rate. The hydraulic parameters studied were coefficient uniformity (CU), emission uniformity (EU), coefficient of variation (CV), and emitter flow variation (EFV). The results showed that $\mathrm{CU}, \mathrm{CV}$, and EU have an excellent classification, with a value of over $95 \%$ efficiency for $\mathrm{CU}$ and the EU. The CV value is less than 0.03 , indicating a very accurate classification. Meanwhile, when running at 2.5 and 2.0 bars, emitter flow variance was $10 \%$ and was considered as the desirable classification. On the contrary, the emitter flow variation was reported at $6 \%$ for 1 bar operating pressure and the classification was also recorded in the desired classification. The results concluded that the use of low operating pressure compared to the minimum operating pressure proposed by the manufacturer can also operate in excellent condition according to the hydraulic parameters evaluated.
\end{abstract}

Keywords: Drip irrigation; pressure compensated; hydraulic performance; low operating pressure

Received: $24^{\text {th }}$ March 2021

Received in revised form: $14^{\text {th }}$ June 2021

Citation: Sharu EH. Hydraulic performance analysis of drip irrigation system using pressure compensated dripper

Accepted: $20^{\text {th }}$ June 2021

Available Online: $2^{\text {nd }}$ July 2021 at low operating pressure. Adv Agri Food Res J 2022; 3(1): a0000225. https://doi.org/10.36877/aafrj.a0000225 


\section{Introduction}

Irrigation is the most important component of agricultural activities. Good irrigation can provide optimal growth to the crop. To achieve this goal, drip type irrigation is used especially for crops such as vegetables and fruits grown either in the greenhouse or in the field. The drip irrigation has been widely used worldwide because it is easy to operate and uses a small pump compared to other irrigation methods. Furthermore, compared to other irrigation methods, drip irrigation have shown to increased crop yields and saved water by about 50\%. (Sivanappan, 1994). This would make investing in a drip irrigation system more affordable, compensating for the high cost of capital for drip equipment (Dhawan, 2000). Drip irrigation provides water to the plant uniformly with a certain amount as required by the crop. Water requirements are different for each crop, and so the crop's water needs can be determined according to the time needed for the irrigation activities to be performed with drip irrigation.

Performance is the basis for drip irrigation. A significant factor in running a drip irrigation system is in its optimum performance. Optimum irrigation operation can be provided by using proper pressure operation (Tyson \& Cutis (2009). The pressure needed must correspond to the quantity of flow required for the irrigation field. This ensures that each dripper's flow rate is uniform, especially for drip irrigation systems using uncompensated dripper type. A pressure compensated dripper can have a uniform flow rate if the pressure is kept within a certain range. Most farmers prefer to use the pressure compensated dripper as compared to the use of uncompensated dripper because it is easier in determining the appropriate use of the pump. Besides, a uniform water flow can be obtained with the use of proper pressure operation.

Uniformity in the distribution of water for crops is the most important element in determining the efficiency of an irrigation system. Apart from proper pressure operation, clogging is also a problem that often disrupts the drip irrigation system. Clogging usually occurs if irrigation is done in conjunction with fertilization. Therefore, selecting a suitable dripper and avoiding the occurrence of clogging is necessary (Zhou et al., 2017).

Studies by Sharu and Razak (2020) has given an excellent classification for all hydraulic parameters measured according to the ASAE standard, using pressure operations within the range required by the dripper. The pressure operation recommended for this study by the manufacturer of drippers is about 1.5-4 bars. This means that excellent hydraulic efficiency would be provided using pressure operation within a certain range for a specific dripper. However, the use of pressure operations in the appropriate range was often unable to be carried out due to many factors, such as small pumps, large quantities of crops, etc. Therefore, this study was conducted to determine the hydraulic performance of using low operating pressure in comparison to the operating pressure recommended by the dripper manufacturer. 


\section{Materials and Method}

\subsection{Study Sites}

Laman Sayur at Malaysia Agro Exposition Park Serdang (MAEPS) was the site of this study. MAEPS is an open showground with pergola-hung vegetables and fruits and a greenhouse area with fertigation and hydroponic vegetables.

MAEPS' drip irrigation system method was used in combination with the fertigation on the Laman Sayur. Two $30 \mathrm{~m}$ long lateral pipes were split into two parts and different valves separate each section for each part. One dripper was fitted for each plant. In this study, the dripper used in the irrigation system was the pressure compensating type (Figure 1) with $2 \mathrm{l} / \mathrm{h}$ discharge and operating pressures of 1.5-4 bars. The irrigation system configuration is as shown in Figure 2. Volumetric methods were used to determine the flow rate for each dripper. Measuring cylinders, stopwatches, and trapped cans were used to measure the dripper flowrate.

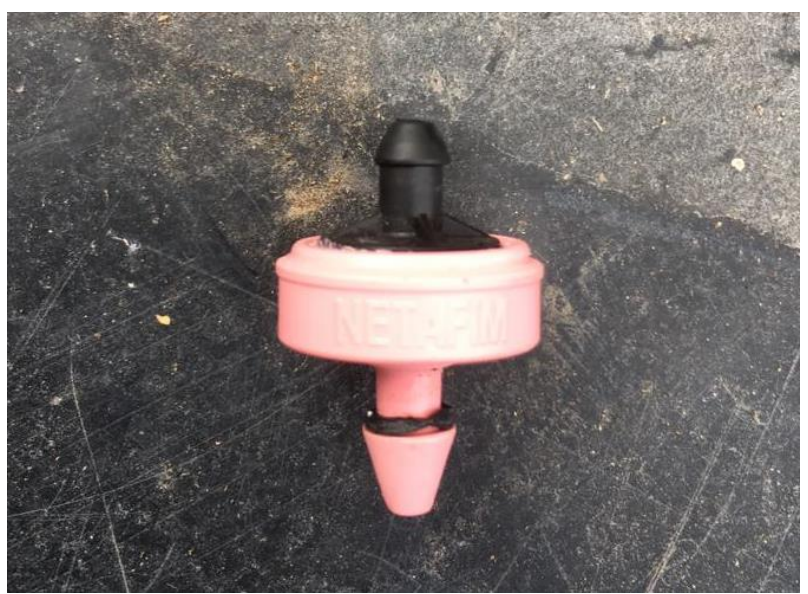

Figure 1. Emitter used in this study

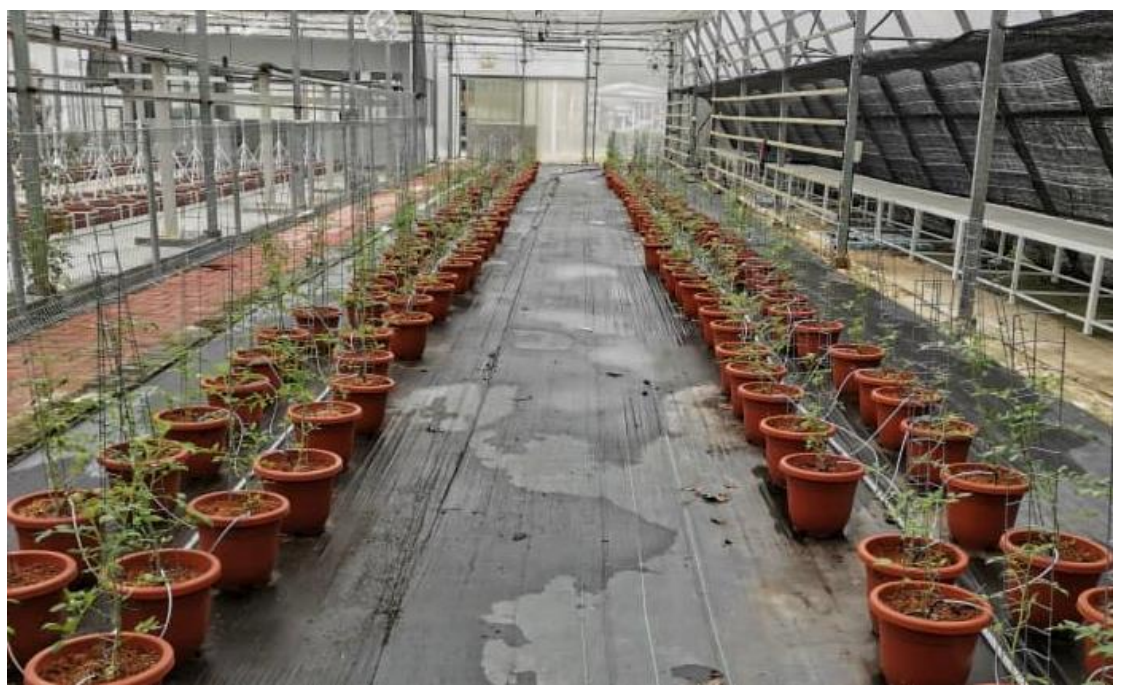

Figure 2. Drip Irrigation system at Laman Sayur, MAEPS Greenhouse 


\subsection{Hydraulic Performance of Drip Irrigation System}

In order to determine the irrigation system's real capacity, hydraulic performance was measured. The coefficient of uniformity (CU), emission uniformity (EU), coefficient of variation of emitter flow $(\mathrm{CV})$, and emitter flow variation $(\mathrm{EFV})$ were factors that were found to influence the hydraulic performance efficiency. These hydraulic parameters were then determined by following the equations of 1 to 4 and indicators as listed in Table 1, as described by the American Society of Agricultural Engineers (ASAE, 1999). Flow rate measurements of each dripper were performed using operating pressures 1.0 bar which was a lower pressure than the minimum pressure recommended by the dripper manufacturer, which was 1.5 bars. This study was conducted using a pressure of 1 bar instead of the pressure recommended by the dripper manufacturer ( 2 and 2.5 bars). Other than that, the experiments were carried out in a similar arrangement of experimental setup and condition performed by Sharu \& Razak (2020) to avoid inconsistent data.

Table 1. Equation and classification involved in hydraulic performance calculation Source from American Society of Agricultural Engineering (ASAE, 1999).

\begin{tabular}{lll}
\hline Parameter & & Performance indicator \\
\hline Coefficient & $\geq 90 \%$ & Excellent \\
of & $80-90 \%$ & Good \\
uniformity & $70-80 \%$ & Fair \\
(CU) & $60-70 \%$ & Poor \\
& $>60 \%$ & Unacceptable \\
Emission & $\geq 90 \%$ & Excellent \\
uniformity & $80-90 \%$ & Good \\
(EU) & $70-80 \%$ & Fair \\
& $\leq 70 \%$ & Poor \\
Coefficient & $<0.05$ & Excellent \\
of variation & $0.07-0.07$ & Average \\
(CV) & $0.11-0.15$ & Marginal \\
& $>0.15$ & Poor \\
Emitter & $\leq 10 \%$ & Unacceptable \\
flow & $10-20 \%$ & Desirable \\
variation & $>25 \%$ & Acceptable \\
(EFV) & & Unacceptable \\
\hline
\end{tabular}

\subsection{Coefficient of Uniformity $(C U)$}

The measuring of coefficient uniformity is using equation defined by (ASAE, 1999) as equation 1: 


$$
C u=100\left(1-\sum \frac{\Delta q}{q n}\right)
$$

Where:

$\mathrm{Cu}=$ Coefficient uniformity in percentage

$\Delta q=$ Average deviation of individual emitters discharge $(1 / \mathrm{h})$.

$q=$ Average discharge $(1 / \mathrm{h})$.

$\mathrm{n}=$ Number of observations.

\subsection{Emission Uniformity (EU)}

Emission uniformity (EU) measured using equation 2 defines by (ASAE, 1999)

$$
\left.E U=100 \frac{q n}{q \mathrm{a}}\right)
$$

Where:

$\mathrm{Eu}=$ Emission uniformity in percentage

$q \mathrm{n}=$ Average discharge of the lowest one fourth of emitter discharge readings $(\mathrm{l} / \mathrm{h})$

$q \mathrm{a}=$ Average discharge of all the emitters $(\mathrm{l} / \mathrm{h})$.

\subsection{Coefficient of Variation (CV)}

The measuring of coefficient of variation using equation 3 below (ASAE, 1999):

$$
C V=100 \frac{S D}{q-}
$$

Where:

$\mathrm{CV}=$ Coefficient of variation .

$\mathrm{SD}=$ Standard deviation of emitter discharge.

$q^{-}=$Average emitter discharge in the same lateral lines $(1 / \mathrm{h})$

\subsection{Emitter Flow Variation (EFV)}

The measuring of emitter flow variation using equation 4 below (ASAE, 1999):

$$
\mathrm{EFV}=100[1-Q \min / Q \max ]
$$

Where:

$\mathrm{EFV}=$ emitter flow variation in percentage

Qmin $=$ minimum emitter discharge rate $(1 / \mathrm{h})$

Qmax $=$ maximum emitter discharge rate $(1 / \mathrm{h})$ 


\section{Results}

\subsection{Hydraulic Performance}

Table 2 shows the hydraulic performance analysis of drip irrigation with low running pressure and operating pressure within the dripper manufacturer's range (Sharu \& Razak, 2020). The drip irrigation system's hydraulic performance analysis was assessed using three different operating pressures. The parameters of CU, CV, EU, and EFV were examined. The results demonstrated that when running at low operating pressure, the drip irrigation system worked well. All hydraulic parameters indicated that they were in excellent classification. A study conducted by (Sharu \& Razak, 2020) found that the use of pressure operation at the range set by the dripper manufacturer showed that all the hydraulic parameters calculated were in an excellent classification.

Table 2. Hydraulic parameters of drip irrigation system values and classification (pressure 2 bars and 2.5 bar study from Sharu and Razak (2020)).

\begin{tabular}{|c|c|c|c|c|}
\hline \multirow{2}{*}{ No. } & \multirow{2}{*}{ Hydraulic parameter } & \multicolumn{3}{|c|}{ Pressure (bar) } \\
\hline & & 1 & 2 & 2.5 \\
\hline 1 & $\begin{array}{l}\mathrm{CU} \\
\text { Classification }\end{array}$ & $\begin{array}{c}98.52 \\
\text { excellent }\end{array}$ & $\begin{array}{c}98.28 \\
\text { excellent }\end{array}$ & $\begin{array}{c}98.23 \\
\text { excellent }\end{array}$ \\
\hline 2 & $\begin{array}{l}\mathrm{CV} \\
\text { Classification }\end{array}$ & $\begin{array}{c}0.018 \\
\text { excellent }\end{array}$ & $\begin{array}{c}0.021 \\
\text { excellent }\end{array}$ & $\begin{array}{c}0.021 \\
\text { excellent }\end{array}$ \\
\hline 3 & $\begin{array}{l}\text { EU } \\
\text { Classification }\end{array}$ & $\begin{array}{c}98.2 \\
\text { excellent }\end{array}$ & $\begin{array}{c}97.53 \\
\text { excellent }\end{array}$ & $\begin{array}{c}97.12 \\
\text { excellent }\end{array}$ \\
\hline 4 & $\begin{array}{l}\text { EFV } \\
\text { Classification }\end{array}$ & $\begin{array}{c}6 \\
\text { desirable }\end{array}$ & $\begin{array}{c}10 \\
\text { desirable }\end{array}$ & $\begin{array}{c}10 \\
\text { desirable }\end{array}$ \\
\hline
\end{tabular}

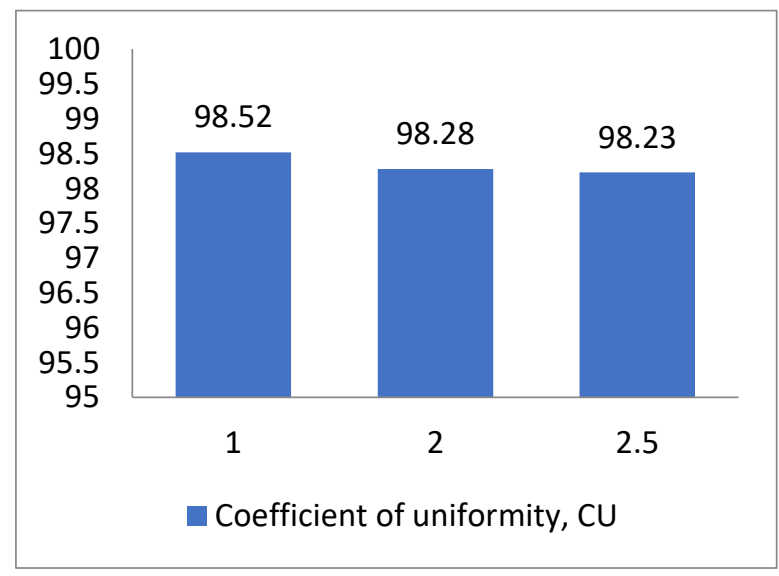

Figure 3. Coefficient of Uniformity

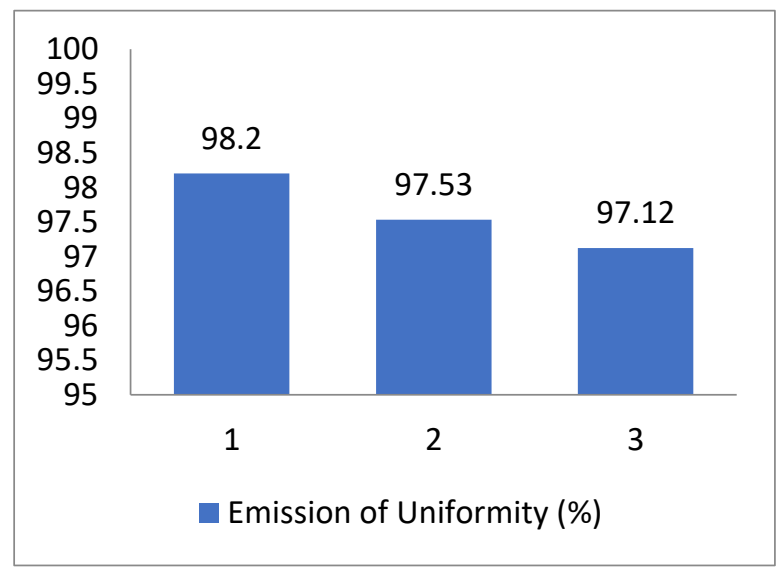

Figure 4. Emission of Uniformity

\subsection{Coefficient of Uniformity (CU)}

The CU showed that excellent classifications (Figure 3) were observed for three distinct operating pressures. The coefficient uniformity for low operational pressure was 
found to be $98.52 \%$ ( 1 bar). While for 2 and 2.5 bars, operating pressure also performed at excellent classification with $98.28 \%$ and $98.23 \%$, respectively. As a result, the emitter discharge for this analysis was done at a low operating pressure, which resulted in an excellent CU result. This suggested that the pressure operation at 1 bar used in this analysis was appropriate for achieving high CU values. To put it another way, it is preferable to use less power rather than more power.

\subsection{Emission of Uniformity $(E U)$}

At 1 bar, 2 bars, and 2.5 bars of operational pressures, the EU coefficients were at $98.2 \%, 97.53 \%$, and $97.12 \%$, respectively. Figure 4 shows that EU was better at 1 bar (low pressure) operating pressure, but the results were still good at 2.0 and 2.5 bars operating pressure, and the classification was excellent. This result showed that the use of low operating pressure gave the best EU value.

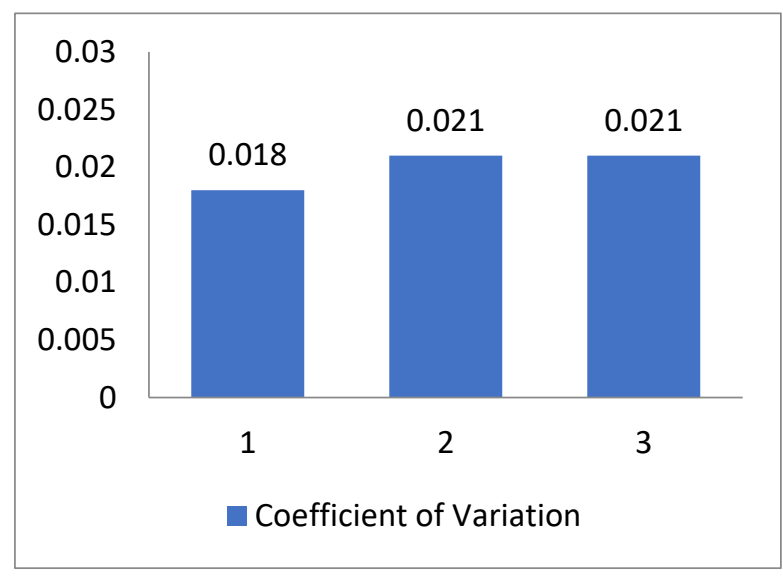

Figure 5. Coefficient of variation

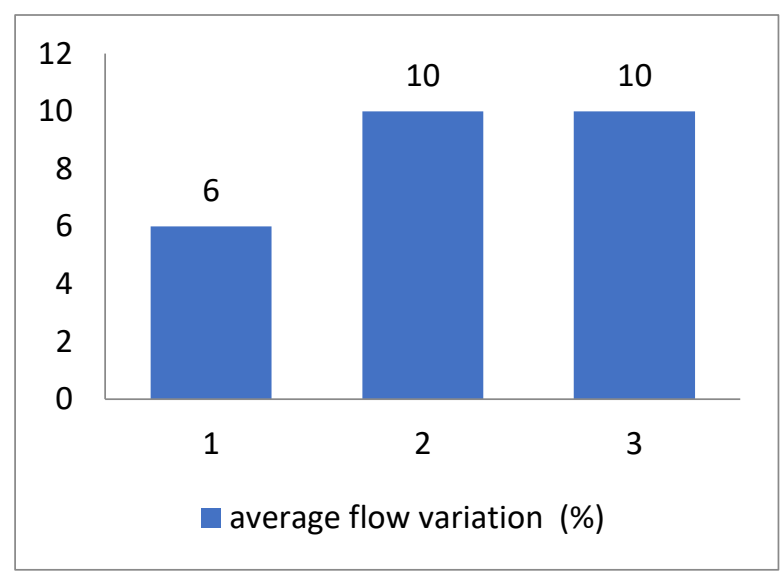

Figure 6. Emitter flow variation

\subsection{Coefficient of Variation (CV)}

With the CV (Figure 5) at 1 bar of operating pressure, the emitter was found to be 0.018 , and at 2 and 2.5 bars of operating pressure, it was found to be 0.021 . According to the findings, it was observed with the decrease in the drip system's operating pressure, the CV decreases as well, which implied that the pressure has a direct impact on the emitter's discharge volume. However, within the three different operational pressures, the classification was still excellent. As a result, the emitter discharge was used with low operating pressure for this analysis, which resulted in an excellent $\mathrm{CV}$.

\subsection{Emitter Flow Variation (EFV)}

The EFV was measured at $6 \%, 10 \%$, and $10 \%$ for operating pressures of 1 bar, 2 bars, and 2.5 bars, respectively. It was evident from Figure 6 that at 1 bar operating pressure, the EFV was the best at $6 \%$. The emitter flow variation at 2.0 and 2.5 bar operating pressures 
gave the variation at $10 \%$. The three distinct operational pressures were classified in the same way as desirable. This means that increased operational pressure can result in a lot of variation. Consequently, the low operating pressure emitter discharge produces the desired result in emitter flow variance in this analysis.

\section{Discussions}

The drip irrigation system's hydraulic performance analysis was assessed with three different operating pressures. The findings demonstrated that when running at a certain operating pressure, the drip irrigation system works well (Sharu \& Razak, 2020). Solomon (1983) and Amound (1995) noted that each applies to a well-planned drip irrigation system if the $\mathrm{CV}$ is at least $85 \%$ and the EU is higher than $90 \%$.

The use of a low operating pressure operation at 1 bar also indicated that it is in an excellent classification and that it was greater than the operating pressure in the range recommended by this dripper manufacturer, also for all parameters. The use of low-pressure activity in this irrigation system indicated that these results will further reduce the power of operating this irrigation system. The use of pressure operation at 1 bar can provide the best performance compared to pressure operation in the range recommended by dripper manufacturers. These findings are important to ensure optimal energy use. Optimal use of energy can save operating costs for the operation of irrigation systems.

\section{Conclusion}

The results concluded that the use of low operating pressure compared to the minimum operating pressure proposed by the manufacturer can also operate in excellent condition according to the hydraulic parameters evaluated. This shows that the choice of a 1 bar pressure procedure in this study was sufficient for obtaining an outstanding classification in the $\mathrm{CU}, \mathrm{EU}$, and $\mathrm{CV}$. For EFV, the result for 1 bar operating pressure gave desirable classification that was better than 2 bars and 2.5 bars pressure operations. The use of 1 bar pressure operation on this irrigation system was sufficient to obtain the best hydraulic performance, although the pressure operation proposal from the dripper manufacturer is in the range of 1.5-4 bars. To put it another way, it is preferable to use less power rather than more power. The results of this drip irrigation system hydraulic efficiency review would aid in determining the appropriate operating pressure level, the type of emitter, and the distance between the emitter and each emitter's discharge.

Author Contributions: Conducting the experiment, collecting data and reviewing the results, as well as preparing and editing the manuscript.

Funding: This study did not receive any outside funding.

Acknowledgments: The authors acknowledge the Laman Sayur MAEPS for providing the study site.

Conflicts of Interest: There are no conflicts of interest declared by the authors. 


\section{References}

Amound, A. L. (1995). Significance of energy losses due to emitter connections in trickle irrigation lines. Journal of Agricultural Engineering Research, 60, 1-5.

ASAE. (2003). Field Evaluation of Micro Irrigation Systems 2003; EP458; American Society of Agricultural Engineers: St. Joseph, MI, USA, pp. 760-765.

Dhawan, B. (2000). Drip irrigation: Evaluating returns. Economic Political Weekly, 35, 3775-3780.

Pragna, G., Kumar, G. M., Shankar, M. S. (2017). Hydraulic performance evaluation of drip system by developing relationship between discharge and pressure. International Journal of Pure \& Applied Bioscience 5, 758-765

Sharu, E. H. \& Razak, M. S. A. (2020). Hydraulic performance and modelling of pressurized drip irrigation system. Water 12, no. 8: 2295. https://doi.org/10.3390/w12082295

Sivanappan, R.K. (1994). Prospects of micro-irrigation in India. Irrigation and Drainage Systems, 8, 49-58.

Solomon, K. H. (1983). Irrigation uniformity and yield theory [Ph.D. Thesis]. Department of Agricultural and Irrigation Engineering, Utah State University, Logan, UT, USA.

Tyson, T. W., Curtis, L. M. (2009). Evaluating water distribution uniformity in micro-irrigation systems. Available from https://studylib.net/doc/18713005/evaluation-water-distribution-uniformity

Zhou, B., Li, Y., Song, P., et al. (2017). Anti-clogging evaluation for drip irrigation emitters using reclaimed water. Irrigation Science 35, 181-192.

Copyright (C) 2021 by Sharu, E. H. and HH Publisher. This work is licensed under the Creative Commons 